\title{
具有肝靶向潜力的马蹄金素衍生物合成及抗乙肝活性研究
}

\author{
袁 洁 $a, b$ 刘青川 ${ }^{c}$ 徐广灿 ${ }^{a, d}$ 胡占兴 ${ }^{a}$ 梁光平 $a$ 黄正明 $c$ \\ 刘昌孝 ${ }^{e}$ 梁光义 $*, a, d$ 徐必学 $*, a$ \\ ( ${ }^{a}$ 贵州省中国科学院天然产物化学重点实验室 贵阳 550002) \\ ( ${ }^{b}$ 贵州大学药学院 贵阳 550002)

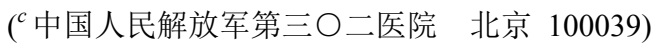 \\ ( $d$ 贵阳中医学院 贵阳 550002) \\ (e天津药物研究院 天津 300193)
}

\begin{abstract}
摘要 为了提高马蹄金素(MTS)衍生物在肝脏病变部位的药物浓度, 增强其抗乙肝病毒活性, 设计并合成了 5 个半乳糖 糖基化修饰的具有肝靶向潜力的 MTS 衍生物, 通过 ${ }^{1} \mathrm{H} N M R,{ }^{13} \mathrm{C}$ NMR, ${ }^{1} \mathrm{H}-{ }^{1} \mathrm{H}$ COSY, HMQC 和 ESI-MS 对其进行了结 构表征, 并用 HepG2 2.2.15 细胞模型初步评价了合成所得目标化合物的抗乙肝病毒(HBV)活性. 结果表明, 所有目标化 合物对 HBV DNA 的复制均有抑制作用，且具有一定的量效关系.
\end{abstract}

关键词＼cjkstart肝靶向; 马蹄金素衍生物; 合成; 抗 HBV 活性

\section{Synthesis and Anti-hepatitis B Virus Activities of Matijin-Su Derivatives with Potential for Hepatic Targeting}

\author{
Yuan, Jie $^{a, b} \quad$ Liu, Qingchuan $^{c} \quad$ Xu, Guangcan ${ }^{a, d} \quad$ Hu, Zhanxing ${ }^{a} \quad$ Liang, Guangping ${ }^{a}$ \\ Huang, Zhengming ${ }^{c} \quad$ Liu, Changxiao ${ }^{e} \quad$ Liang, Guangyi ${ }^{*, a, d} \quad \mathrm{Xu}$, Bixue $^{*, a}$ \\ ( ${ }^{a}$ Key Laboratory of Chemistry for Natural Products of Guizhou Province and Chinese Academy of Sciences, \\ Guiyang 550002) \\ ( ${ }^{b}$ College of Pharmacy, Guizhou University, Guiyang 550002) \\ ( 302 Hospital of PLA, Beijing 100039) \\ ( ${ }^{d}$ Guiyang College of Traditional Chinese Medicine, Guiyang 550002) \\ ( ${ }^{e}$ Tianjin Institute of Pharmaceutical Research, Tianjin 300193)
}

\begin{abstract}
To improve the concentration in liver lesion tissue and increase the anti-hepatitis B virus (HBV) activity of Matijin-Su [ $N$-( $N$-benzoyl-L-phenylalanyl)- $O$-acetyl- $L$-phenylalanol, MTS] derivatives, five galactosyl derivatives of MTS with potential for hepatic targeting were synthesized and their structures were confirmed by ${ }^{1} \mathrm{H}$ NMR, ${ }^{13} \mathrm{C}$ NMR, ${ }^{1} \mathrm{H}-{ }^{1} \mathrm{H} \mathrm{COSY}$, HMQC and ESI-MS. The anti-HBV activities of those compounds were evaluated in HepG2 2.2.15 cells. The screening results showed that all target compounds had inhibitory effect on HBV DNA replication in HepG2 2.2.15 cells in a dose-effect relationship.
\end{abstract}

Keywords hepatic targeting; Matijin-Su derivatives; synthesis; anti-hepatitis B virus activity

乙型肝炎是由乙肝病毒(HBV)感染引起的, 全球约 有 20 亿人感染 $\mathrm{HBV}^{[1]}$. 到目前为止, 还没有药物能够彻 底清除体内 HBV 并最终治愈乙肝, 因此, 发现和开发 具有独特化学结构的创新药物显得尤为重要. 本研究组
从苗族药马蹄金 (Dichondra repens Forst)中分离得到一 新结构类型的抗 HBV 化合物马蹄金素 $[N-(N$ - 苯甲酰基1-苯丙氨酰基)- $O$-乙酰基-1-苯丙氨醇, MTS](如图 1 所 示), 通过以 MTS 为先导化合物, 设计并合成了一系列

\footnotetext{
*E-mail: guangyi_liang@126.com; bixue_xu@126.com

Received May 7, 2015; revised June 8, 2015; published online June 19, 2015.

Project supported by the National Natural Science Foundation of China (No. 81360472) and the Western Light Talent Culture Project (2014).

国家自然科学基金(No. 81360472)和西部之光人才 (2014 年)资助项目.
} 
具有抗 HBV 活性的 MTS 衍生物 ${ }^{[2 \sim 5]}$. 对其中 1 个具有 体内外抗 HBV 活性均较好的 MTS 衍生物(代号 Y101) 进行了深入系统的临床前研究, 获得了国家食品药品监 督管理局颁发的临床批件 (原料药及其制剂批件号: 2013L02491，2014L00070)，目前正在进行该药物的 I 期 临床试验. 该衍生物的体内吸收和分布等初步的药物代 谢动力学实验表明, 其在组织中分布广泛, 在肝脏组织 中的浓度不太高. 因此, 为提高该类化合物在肝脏病变 部位的药物浓度, 减少其全身分布, 以进一步提高其抗 乙肝病毒的活性, 减轻其毒副作用, 本文拟对 MTS 衍生 物进行肝靶向药物设计与合成.

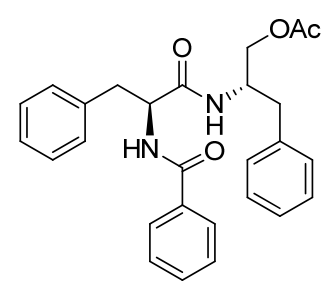

图 1 MTS 的化学结构式

Figure 1 Chemical structure of MTS

去唾液酸糖蛋白受体(Asialoglycoprotein Receptor, ASGP-R $)^{[6]}$ 是哺乳动物肝实质细胞特有的一种高效内吞 受体, 能专一性识别、结合并内吞循环血液中含末端带 有非还原 $D$-半乳糖和 $N$-乙酰- $D$-氨基半乳糖的葟糖或糖 蛋白, 主动转运至肝细胞内部, 使其在肝细胞内进行代 谢. 将小分子药物直接与半乳糖结合可产生较好的肝靶 向效果. 方唯硕等 ${ }^{[7]}$ 在熊果酸的 3 位或(和) 28 位引入半 乳糖, 借助半乳糖所具有的肝靶向作用, 增加了其保肝 效果. Huang 等 ${ }^{[8,9]}$ 成功制备了一氧化氮供体型齐墩果酸 半乳糖衍生物, 活性实验表明其对人肝癌细胞显示出较 好的专属性识别功能. 据此, 我们在 MTS 衍生物上引入 半乳糖基, 设计了一系列的具有肝靶向潜力的 MTS 衍 生物(图 2), 期望能够提高该类化合物在肝脏病变部位 的药物浓度, 增强其抗 HBV 活性.

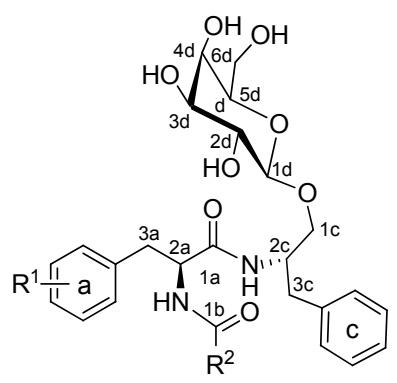

图 2 肝靶向 MTS 衍生物的结构通式

Figure 2 General structure of hepatic targeting MTS derivatives

以 1-苯丙氨醇为原料, 依次采用邻苯二甲酸酐对其
氨基进行选择性保护得到中间体 $\mathbf{2}$, 以全乙酰化的半乳 糖作为糖给体对其醇羟基进行直接糖基化，得到中间体 3. 中间体 3 在水合肼条件下脱去所有保护基团, 再以二 碳酸二叔丁酯 $\left[(\mathrm{Boc})_{2} \mathrm{O}\right]$ 选择性保护氨基，而后对糖上的 游离羟基进行乙酰化即得中间体 $\mathbf{6}$, 中间体 $\mathbf{6}$ 在三氟乙 酸作用下脱 Boc 保护基, 得到关键中间体 7. 同时以 1苯丙氨酸甲酯盐酸盐、1-酪氨酸甲酯盐酸盐为原料经缩 合、水解、烷基化反应合成中间体 $11 \mathrm{a} \sim 11 \mathrm{e}$. 再将 11a 11e 分别和 7 在氯甲酸异丁酯( IBCF) $/ N$-甲基吗啡啉 (NMM) 作用下形成酰胺键即得 $12 \mathbf{a} \sim 12 \mathrm{e}$, 最后再对其 进行脱乙酰基保护即得目标化合物 $13 \mathbf{a} \sim 13 \mathrm{e}$. 所有目 标化合物均经 ${ }^{1} \mathrm{H}$ NMR, ${ }^{13} \mathrm{C}$ NMR, ${ }^{1} \mathrm{H}-{ }^{1} \mathrm{H}$ COSY, HMQC 和 ESI-MS 进行了结构确认, 并评价了其对 HepG2 2.2.15 细胞内 HBV DNA 表达量的影响. 目标化合物的 合成路线见 Scheme 1.

\section{1 结果与讨论}

\section{1 合成方法}

为了得到目标化合物，曾尝试多种方法对 MTS 衍 生物的 1c-位醇羟基进行直接糖基化，但是均未成功. 包括以不同的糖给体结合相应的反应条件，如： $1,2,3,4,6$-五- $O$-乙酰基- $\beta$ - $D$-吡喃半乳糖 $\left(\mathrm{BF}_{3} \cdot \mathrm{Et}_{2} \mathrm{O}\right)^{[10,11]}$ 、 $2,3,4,6$ - 四- $O$-乙酰基- $\alpha$ - $D$ - 溴代吡喃半乳糖 (AgOTf、

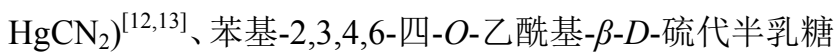
苷(NIS/TfOH、NBS $)^{[14,15]}$ 和半乳糖基三氯乙酰亚胺酯 $\left(\mathrm{BF}_{3} \cdot \mathrm{Et}_{2} \mathrm{O} 、 \mathrm{TMSOTf}\right)^{[16,17]}$. 因此, 本文采用 Scheme 1 所 示的合成路线, 先对邻苯二甲酰保护的苯丙氨醇进行糖 基化后得中间体 3 , 而后经选择性保护和脱保护反应得 含游离氨基的中间体 7, 再将其与中间体 $11 \mathrm{a} \sim 11 \mathrm{e}$ 缩合, 合成得目标化合物. 从中间体 3 合成中间体 7 时，曾尝 试用 $\mathrm{TsOH} \cdot \mathrm{H}_{2} \mathrm{O}^{[18]}$ 和 $\mathrm{N}_{2} \mathrm{H}_{4} \cdot \mathrm{H}_{2} \mathrm{O}^{[19,20]}$ 选择性脱去邻苯二 甲酰保护基，同时保留糖基上乙酰基，但均未成功，最 终采用了四步反应一锅法完成, 收率 $26 \%$. 在合成中间 体 12a $\sim 12 \mathrm{e}$ 时, 以 $\mathrm{CH}_{2} \mathrm{Cl}_{2}$ 单一溶剂较 $\mathrm{DMF} / \mathrm{CH}_{2} \mathrm{Cl}_{2}$ 混 合反应溶剂所得产物的收率高, 若以 DMF 作为单一反 应溶剂, 则反应收率很低.

\section{2 氧苷键构型的确证}

在糖基化过程中，利用半乳糖 2-位羟基上乙酰基的 邻基参与效应, 可立体特异性地生成 $\beta$-型糖苷键, 所得 目标化合物的氢谱中, 13a 和 13e 的 $J_{1 \mathrm{~d}, 2 \mathrm{~d}}$ 分别为 7.7, 7.6 $\mathrm{Hz}, 13 \mathrm{a} \sim 13 \mathrm{e}$ 的 $\mathrm{C}-1 \mathrm{~d}$ 的化学位移分别为 $\delta 105.46$ 、 103.74、104.13、103.80、105.43. 因此，通过核磁共振 氢谱中半乳糖基的端基质子 $\mathrm{C}^{1}-\mathrm{H}$ 与 $\mathrm{C}^{2}-\mathrm{H}$ 的偶合常数和 $\mathrm{C}^{1}$ 的 ${ }^{13} \mathrm{C}$ 化学位移确认了目标化合物中糖苷键为 $\beta$ 构 型 ${ }^{[21]}$. 

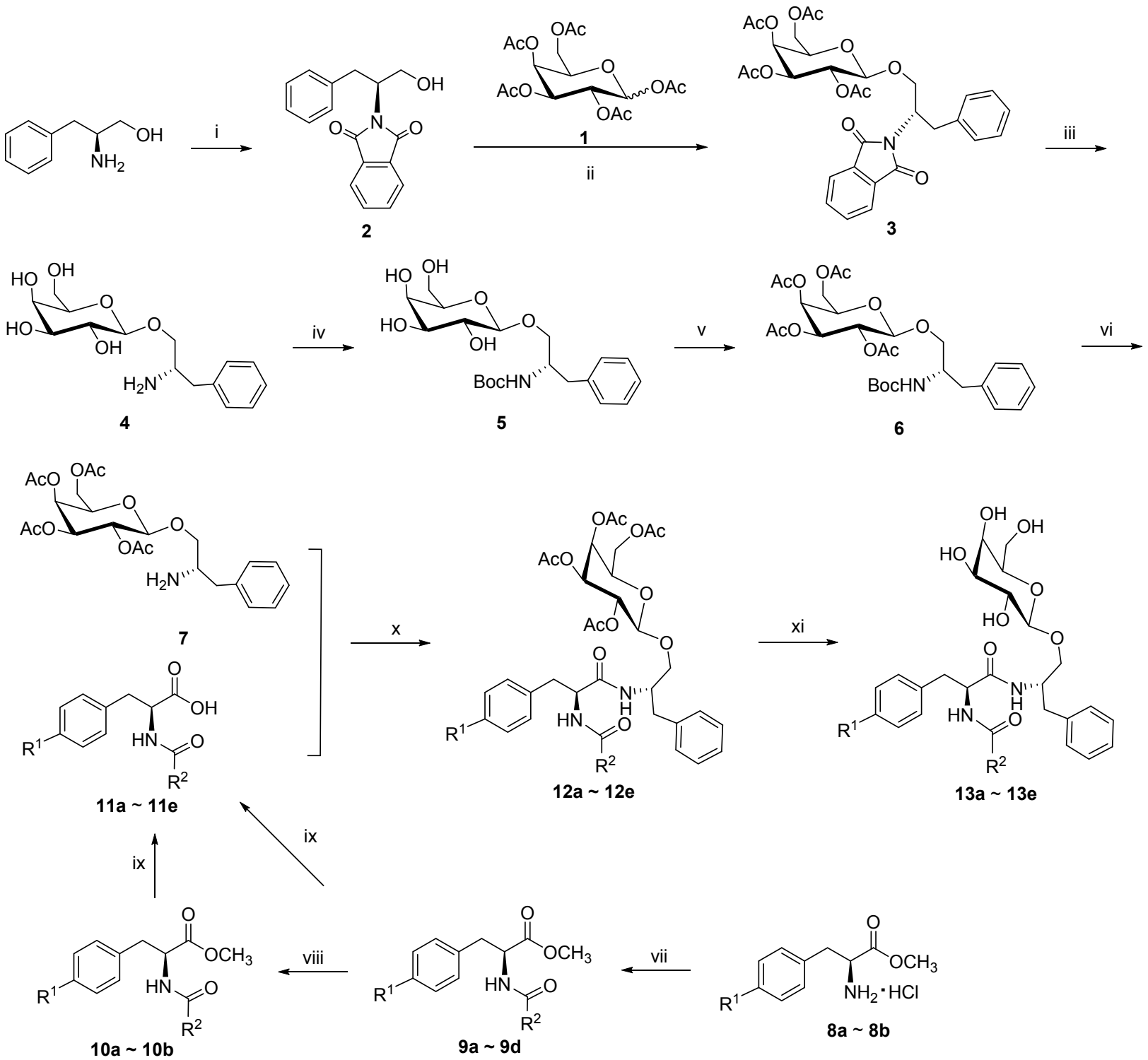<smiles>[R]c1ccc(CC(NC(=O)OC)C(=O)OC)cc1</smiles><smiles>[R]c1ccc(CC(N)C(=O)OCc2ccccc2)cc1</smiles>

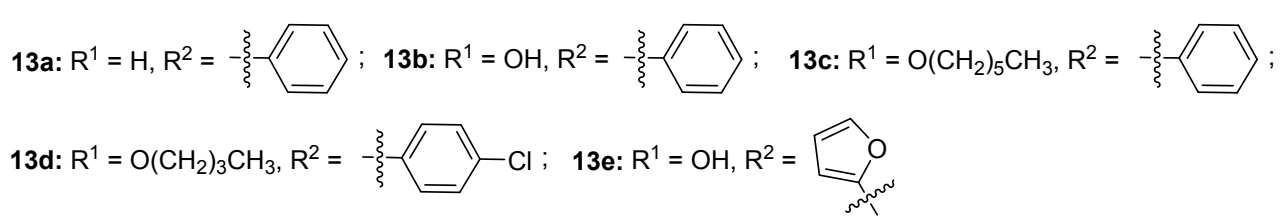

Reagents and conditions: (i) Phthalic anhydride, $\mathrm{Et} 3 \mathrm{~N}$, toluene, $140{ }^{\circ} \mathrm{C}$; (ii) $\mathrm{Et}_{2} \mathrm{O} \cdot \mathrm{BF}_{3}, 4 \AA \mathrm{MS}, \mathrm{CH}_{2} \mathrm{Cl}_{2}, 0{ }^{\circ} \mathrm{C}$ to rt; (iii) $\mathrm{N}_{2} \mathrm{H}_{4} \cdot \mathrm{H} \mathrm{H}_{2} \mathrm{O}, \mathrm{EtOH} / \mathrm{H}_{2} \mathrm{O}, 80{ }^{\circ} \mathrm{C}$; (iv) (Boc) $)_{2} \mathrm{O}, \mathrm{Et}_{3} \mathrm{~N}, \mathrm{CH}_{3} \mathrm{OH}, 45{ }^{\circ} \mathrm{C}$; (v) $\mathrm{Ac}_{2} \mathrm{O}$, pyridine, r.t.; (vi) $\mathrm{CF}_{3} \mathrm{COOH}, \mathrm{CH}_{2} \mathrm{Cl}_{2}$, r.t.; (vii) Benzoic acid or 4-chlorobenzoic acid or 2-furoic acid, isobutyl chloroformate (IBCF)/N-methylmorpholine (NMM), DMF/CH $\mathrm{Cl}_{2}, 0{ }^{\circ} \mathrm{C}$ to r.t.; $\left(\right.$ viii) $\mathrm{CH}_{3}\left(\mathrm{CH}_{2}\right)_{3} \mathrm{l}$ or $\mathrm{CH}_{3}\left(\mathrm{CH}_{2}\right)_{5} \mathrm{Br}, \mathrm{K}_{2} \mathrm{CO}_{3}$, DMF, r.t.; (ix) $1.0 \mathrm{~mol} \cdot \mathrm{L}{ }^{-1} \mathrm{NaOH}$ (aq.), DMF, r.t.; (x) IBCF, NMM, $\mathrm{CH}_{2} \mathrm{Cl}_{2}, 0{ }^{\circ} \mathrm{C}$ to r.t.; (xi) $\mathrm{CH}_{3} \mathrm{ONa}, \mathrm{CH}_{3} \mathrm{OH} / \mathrm{CH}_{2} \mathrm{Cl}_{2}$, r.t.

\section{图式 1 目标化合物的合成路线}

Scheme 1 Synthetic route of target compounds

\section{3 生物活性}

按照第 3.3 节的测试方法检测目标化合物对 HepG2 2.2.15 细胞内 HBV DNA 表达量的影响, 如表 1 所示. 结 果表明, 所有目标化合物对 HBV DNA 的复制均有抑制 作用，且具有一定的量效关系.

\section{2 结论}

以全乙酰化的半乳糖为糖给体, 1-苯丙氨醇、1-酪氨 酸等为原料, 经缩合、水解、烷基化、糖基化、脱乙酰 基等反应步骤，合成了 5 个具有肝靶向潜力的 MTS 衍生 物，并对所得目标产物进行了抗 HBV 活性测试. 
表 1 目标化合物对 HepG2 2.2.15 细胞内 HBV DNA 复制的抑 制率 $(\bar{x} \pm s, n=3)$

Table 1 Inhibition ratio for the replication of HBV DNA of compounds $13 \mathbf{a} \sim 13 \mathbf{e}(\bar{x} \pm s, n=3)$

\begin{tabular}{cccc}
\hline \multirow{2}{*}{ Compd. } & \multicolumn{3}{c}{ Inhibition ratio/\% } \\
\cline { 2 - 4 } & $12.5 \mu \mathrm{g} \bullet \mathrm{mL}^{-1}$ & $25 \mu \mathrm{g} \cdot \mathrm{mL}^{-1}$ & $50 \mu \mathrm{g} \bullet \mathrm{mL}^{-1}$ \\
\hline $13 \mathrm{a}$ & 22.31 & 21.36 & 32.18 \\
$13 \mathrm{~b}$ & 27.03 & 33.43 & 36.24 \\
$13 \mathrm{c}$ & 17.48 & 26.70 & 31.23 \\
$13 \mathrm{~d}$ & 44.24 & 47.21 & 44.28 \\
$13 \mathrm{e}$ & 0.88 & 35.26 & 38.88 \\
$3 \mathrm{TC}$ & & & 97.76 \\
\hline
\end{tabular}

结果表明, 所有目标化合物对 2.2.15 细胞的 HBV DNA 的复制均有抑制作用，且具有一定的量效关系. 下一步 将以此为基础设计合成更多的具有肝靶向潜力的 MTS 衍生物, 并选择抗 HBV 活性较好的衍生物进行其体内 活性测试及肝靶向性研究.

\section{3 实验部分}

\section{1 仪器与试剂}

核磁共振谱以 TMS 为内标, 用 Inova-400 MHz 型超 导核磁共振仪(美国 Varian 公司)测定; 质谱用 HP-5793 质谱仪(美国 Hewlett-Packard 公司)测定; 柱色谱硅胶 (300 400 目)及高效薄层板均为青岛海洋化工厂产品. 其余试剂均为市售分析纯或化学纯产品, 除特别说明 外, 未经处理直接使用.

\section{2 化学合成}

3.2.1 糖供体 1,2,3,4,6-五- $O$-乙酰基- $\beta$ - $D$-吡喃半乳糖 (1) 的合成

糖供体 1 参照文献[22]的方法制备.

\subsection{2中间体 $N$-邻苯二甲酰-1-苯丙氨醇(2)的合成}

取 1 -苯丙氨醇 $(3.00 \mathrm{~g}, 19.8 \mathrm{mmol})$ 和邻苯二甲酸酐 (2.94 g, $19.8 \mathrm{mmol})$ 于装备了迪安-斯脱克分水器 (Dean-Stark tube)的反应瓶中, 加入甲苯 $(80 \mathrm{~mL})$ 和三乙 胺(4.15 mL, $29.86 \mathrm{mmol})$, 室温摚拌混匀, 再于 $140{ }^{\circ} \mathrm{C}$ 回流 $3.5 \mathrm{~h}$. 待反应液冷却至室温后, 将其分散于乙酸乙 酯(500 mL)和水(400 mL)中, 萃取, 所得有机层依次以 $0.1 \mathrm{~mol} \cdot \mathrm{L}^{-1}$ 盐酸水 $(300 \mathrm{~mL})$ 、饱和碳酸氢钠溶液 $(300$ $\mathrm{mL} \times 2)$ 和饱和氯化钠 $(300 \mathrm{~mL} \times 2)$ 洗涤, 无水硫酸镁干 燥, 减压回收溶剂至干, 所得残留物经硅胶柱层析 $[V($ 氯 仿) : $V$ (甲醇 $)=70: 1$ ] 纯化, 得 $5.29 \mathrm{~g}$ 白色粉末中间体 $2^{[23]}$, 收率 95\%. m.p. 120 121 ${ }^{\circ} \mathrm{C} ;{ }^{1} \mathrm{H}$ NMR (400 MHz, $\left.\mathrm{CDCl}_{3}\right) \delta: 7.80 \sim 7.73(\mathrm{~m}, 2 \mathrm{H}, \mathrm{H}$-arom. $), 7.70 \sim 7.63(\mathrm{~m}$, $2 \mathrm{H}, \mathrm{H}$-arom.), $7.24 \sim 7.12(\mathrm{~m}, 5 \mathrm{H}, \mathrm{H}-5 \mathrm{c} \sim \mathrm{H}-9 \mathrm{c}), 4.68 \sim$ 4.59 (m, 1H, H-2c), 4.08 (dd, $J=11.7,7.5$ Hz, 1H, H-1c), $3.93\left(\mathrm{dd}, J=11.8,3.6 \mathrm{~Hz}, 1 \mathrm{H}, \mathrm{H}-1^{\prime} \mathrm{c}\right), 3.20$ (d, $J=8.0 \mathrm{~Hz}$,
$2 \mathrm{H}, \mathrm{H}-3 \mathrm{c}) ;{ }^{13} \mathrm{C}$ NMR (101 MHz, $\mathrm{CDCl}_{3}$ ) $\delta: 168.89$ (OC$\mathrm{NCO}), \quad 137.35$ ( $\left.\mathrm{C}_{\text {arom.quat. }}\right), \quad 134.01 \quad\left(2 \mathrm{C}_{\text {arom. }}\right), 131.54$

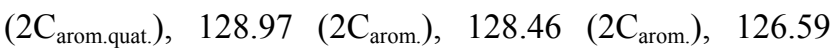
$(\mathrm{C}-7 \mathrm{c}), 123.24$ (2C $\left.\mathrm{C}_{\text {arom. }}\right), 62.72$ (C-1c), 55.18 (C-2c), 34.72 (C-3c).

3.2.3中间体 $N$-邻苯二甲酰- $O-(2,3,4,6$-四- $O$-乙酰基$\beta$ - $D$-吡喃半乳糖基) -1-苯丙氨醇(3)的合成

取中间体 1 (3.33 g, $8.53 \mathrm{mmol})$ 、糖供体 2 (2.00 g, $7.11 \mathrm{mmol})$ 与 $5.70 \mathrm{~g}$ 粉末状 $4 \AA$ 分子笁混合于反应瓶中, 氩气保护下, 注入 $45 \mathrm{~mL}$ 无水 $\mathrm{CH}_{2} \mathrm{Cl}_{2}$, 冰水浴冷却至 $0{ }^{\circ} \mathrm{C}$, 滴加 $\mathrm{BF}_{3} \cdot \mathrm{Et}_{2} \mathrm{O}(6.5 \mathrm{~mL}, 51.2 \mathrm{mmol})$, 滴加完毕后 继续搅拌反应 $48 \mathrm{~h}$ 至 TLC 检测反应完毕. 向反应液中 加入碳酸钾 $(7.00 \mathrm{~g}, 51.2 \mathrm{mmol})$, 室温搅拌 $10 \mathrm{~min}$ 后, 将 其分散到乙酸乙酯 $(500 \mathrm{~mL})$ 和水 $(400 \mathrm{~mL})$ 中, 萃取, 所 得有机层以水洗涤 $(300 \mathrm{~mL} \times 2)$, 无水硫酸镁干燥, 减压 回收溶剂至干, 所得残留物经硅胶柱层析 $[V$ (石油醚) : $V($ 乙酸乙酯 $)=2: 1$ ] 纯化, 得 $2.68 \mathrm{~g}$ 无色油状中间体 $\mathbf{3}$, 收率 62\%. ${ }^{1} \mathrm{H}$ NMR (400 MHz, $\left.\mathrm{CDCl}_{3}\right) \delta: 7.80 \sim 7.75(\mathrm{~m}$, $2 \mathrm{H}, \mathrm{H}$-arom.), $7.71 \sim 7.65$ (m, $2 \mathrm{H}, \mathrm{H}$-arom.), $7.23 \sim 7.12$ (m, 5H, H-5c $\sim \mathrm{H}-9 \mathrm{c}), 5.33$ (dd, $J=3.4,1.0 \mathrm{~Hz}, 1 \mathrm{H}, \mathrm{H}-4 \mathrm{~d})$, 5.10 (dd, $J=10.5,7.9 \mathrm{~Hz}, 1 \mathrm{H}, \mathrm{H}-2 \mathrm{~d}), 4.91$ (dd, $J=10.5$, $3.4 \mathrm{~Hz}, 1 \mathrm{H}, \mathrm{H}-3 \mathrm{~d}), 4.85 \sim 4.74(\mathrm{~m}, 1 \mathrm{H}, \mathrm{H}-2 \mathrm{c}), 4.42$ (d, $J=$ $7.9 \mathrm{~Hz}, 1 \mathrm{H}, \mathrm{H}-1 \mathrm{~d}), 4.24 \sim 4.07$ (m, 4H, H-6d, H-1c), 3.85 (td, $J=6.7,1.0 \mathrm{~Hz}, 1 \mathrm{H}, \mathrm{H}-5 \mathrm{~d}), 3.24$ (dd, $J=13.9,9.8 \mathrm{~Hz}$, $1 \mathrm{H}, \mathrm{H}-3 \mathrm{c}$ ), 3.10 (dd, $J=13.9,6.4 \mathrm{~Hz}, 1 \mathrm{H}, \mathrm{H}-3$ 'c), 2.13 (s, $3 \mathrm{H}, \mathrm{CH}_{3} \mathrm{CO}$ ), 2.04 (s, 3H, $\left.\mathrm{CH}_{3} \mathrm{CO}\right), 1.92$ (s, 3H, $\mathrm{CH}_{3} \mathrm{CO}$ ), $1.55\left(\mathrm{~s}, 3 \mathrm{H}, \mathrm{CH}_{3} \mathrm{CO}\right) ;{ }^{13} \mathrm{C} \mathrm{NMR}\left(101 \mathrm{MHz}, \mathrm{CDCl}_{3}\right) \delta$ : $170.35,170.22,170.07,168.86,168.11,\left(\mathrm{CH}_{3} \mathrm{CO} \times 4\right.$, OCNCO), 136.86 ( $\left.\mathrm{C}_{\text {arom.quat. }}\right), 133.88$ (2 $\left.\mathrm{C}_{\text {arom. }}\right), 131.60$ $\left(2 \mathrm{C}_{\text {arom.quat. }}\right), 128.80 \quad\left(2 \mathrm{C}_{\text {arom. }}\right), 128.52 \quad\left(2 \mathrm{C}_{\text {arom. }}\right), 126.70$ $(\mathrm{C}-7 \mathrm{c}), 123.13$ (2C $\left.\mathrm{C}_{\text {arom. }}\right), 100.93$ (C-1d), 70.74, 70.56, (C-3d, C-5d), 68.48 (C-2d), 68.05 (C-1c), 66.85 (C-4d), 61.12 (C-6d), 52.29 (C-2c), 34.96 (C-3c), 20.65, 20.62, $20.50,19.93\left(\mathrm{CH}_{3} \mathrm{CO} \times 4\right)$.

3.2.4 中间体 $O-(2,3,4,6-$ 四- $O$-乙酰基- $\beta$ - $D$-吡喃半乳 糖基)-1-苯丙氨醇(7)的合成

取中间体 3 (1.00 g, $1.64 \mathrm{mmol})$ 于反应瓶中, 依次加 入 $125 \mathrm{~mL}$ 乙醇, $8 \mathrm{~mL}$ 水, $13.5 \mathrm{~mL}$ 水合肼 $(277 \mathrm{mmol})$, $80{ }^{\circ} \mathrm{C}$ 回流 $1 \mathrm{~h}$ 至反应完全, 减压回收乙醇, 用少量甲苯 共沸至干，得中间体 4. 将所得 4 粗品加入 $60 \mathrm{~mL}$ 甲醇, 于油浴 $45{ }^{\circ} \mathrm{C}$ 加热溶解, 加入二碳酸二叔丁酯 $(0.71 \mathrm{~mL}$, $3.28 \mathrm{mmol})$, 三乙胺 $(0.46 \mathrm{~mL}, 3.28 \mathrm{mmol})$, 继续于 $45{ }^{\circ} \mathrm{C}$ 搅拌 $1 \mathrm{~h}$ 至底物反应完全, 加少量水终止反应, 减压回 收甲醇至干, 得到中间体 $\mathbf{5}$. 所得 $\mathbf{5}$ 以 $16 \mathrm{~mL}$ 吡啶溶解, 冰水浴充分冷却下缓慢加入 $8 \mathrm{~mL}$ 乙酸酎, 滴加完毕, 
室温摚拌 $10 \mathrm{~h}$ 后, 将反应液分散到乙酸乙酯 $(400 \mathrm{~mL})$ 和 冰水 $(300 \mathrm{~mL})$ 混合物中, 萃取, 有机层依次以稀盐酸 $(200 \mathrm{~mL} \times 2)$ 和水 $(200 \mathrm{~mL} \times 2)$ 洗涤, 无水硫酸镁干燥, 减压回收剂至干, 得到中间体 6. 将 6 溶解于 $10 \mathrm{~mL}$ 二 氯甲烷中, 冰水浴冷却下缓慢加入 $10 \mathrm{~mL}$ 三氟乙酸, 滴 加完毕后, 室温搅拌 $30 \mathrm{~min}$ 至 TLC 检测反应完全. 将反 应液分散到乙酸乙酯 $(400 \mathrm{~mL})$ 和冰饱和碳酸钠 $(300 \mathrm{~mL})$ 混合物中, 萃取, 所得有机层以水洗涤 $(250 \mathrm{~mL} \times 3)$, 无 水硫酸镁干燥, 减压回收溶剂至干, 所得残留物经硅胶 柱层析 $[V$ (氯仿) $: V$ (甲醇) $=30: 1$ ]纯化, 得 $200 \mathrm{mg}$ 无色 油状化合物 7, 四步反应总收率 $26 \%$. ${ }^{1} \mathrm{H}$ NMR (400 $\left.\mathrm{MHz}, \mathrm{CDCl}_{3}\right) \delta: 7.38 \sim 7.14(\mathrm{~m}, 5 \mathrm{H}, \mathrm{H}-5 \mathrm{c} \sim \mathrm{H}-9 \mathrm{c}), 5.40$ (dd, $J=3.4,1.1 \mathrm{~Hz}, 1 \mathrm{H}, \mathrm{H}-4 \mathrm{~d}$ ), 5.24 (dd, $J=10.5,7.9 \mathrm{~Hz}$, 1H, H-2d), 5.03 (dd, $J=10.5,3.4 \mathrm{~Hz}, 1 \mathrm{H}, \mathrm{H}-3 \mathrm{~d}$ ), 4.49 (d, $J=7.9 \mathrm{~Hz}, 1 \mathrm{H}, \mathrm{H}-1 \mathrm{~d}$ ), 4.22 4.09 (m, 2H, H-6d), 3.94 $3.89(\mathrm{~m}, 2 \mathrm{H}, \mathrm{H}-5 \mathrm{~d}, \mathrm{H}-1 \mathrm{c}), 3.39 \sim 3.25(\mathrm{~m}, 2 \mathrm{H}, \mathrm{H}-2 \mathrm{c}$, H-l'c), 2.74 (dd, $J=13.3,5.5 \mathrm{~Hz}, 1 \mathrm{H}, \mathrm{H}-3 \mathrm{c}$ ), 2.55 (dd, $J=$ 13.4, $8.0 \mathrm{~Hz}, 1 \mathrm{H}, \mathrm{H}-3$ 'c), 2.16 (s, 3H, $\mathrm{CH}_{3} \mathrm{CO}$ ), 2.07 (s, 3H, $\mathrm{CH}_{3} \mathrm{CO}$ ), 2.04 (s, $3 \mathrm{H}, \mathrm{CH}_{3} \mathrm{CO}$ ), 2.00 (s, $3 \mathrm{H}, \mathrm{CH}_{3} \mathrm{CO}$ ); ${ }^{13} \mathrm{C}$ NMR $\left(101 \mathrm{MHz}, \mathrm{CDCl}_{3}\right) \delta: 170.39,170.24,170.15$, $169.54\left(\mathrm{CH}_{3} \mathrm{CO} \times 4\right), 138.21 \quad(\mathrm{C}-4 \mathrm{c}), 129.14 \quad\left(2 \mathrm{C}_{\text {arom. }}\right)$, 128.55 (2C $\left.\mathrm{C}_{\text {arom. }}\right), 126.48$ (C-7c), 101.57 (C-1d), 74.48 (C-1c), 70.77, 70.58, (C-3d, C-5d), 68.92 (C-2d), 66.93 (C-4d), 61.21 (C-6d), 52.12 (C-2c), 39.92 (C-3c), 20.81 $\left(\mathrm{CH}_{3} \mathrm{CO}\right), 20.66\left(\mathrm{CH}_{3} \mathrm{CO} \times 2\right), 20.58\left(\mathrm{CH}_{3} \mathrm{CO}\right)$.

3.2.5中间体 $9 \mathrm{a} \sim 9 \mathrm{~d} 、 10 \mathrm{a} \sim 10 \mathrm{~b} 、 11 \mathrm{a} \sim 11 \mathrm{e}$ 的合成

中间体 9a 9d、10a $\sim 10 b 、 11 a \sim 11 \mathrm{e}$ 参照文献 $[4,5]$ 的方法制备.

\subsection{6中间体 $12 \mathrm{a} \sim 12 \mathrm{e}$ 的合成}

以中间体 12a 的合成为例. 取 $7(150 \mathrm{mg}, 0.31$ $\mathrm{mmol})$ 和 11a (100 mg, $0.37 \mathrm{mmol}$ 混合于反应瓶中, 加入 无水 $\mathrm{CH}_{2} \mathrm{Cl}_{2}(6 \mathrm{~mL})$ 和 NMM $(80 \mu \mathrm{L}, 0.72 \mathrm{mmol})$, 冰水浴 冷却至 $0{ }^{\circ} \mathrm{C}$, 氩气保护下, 滴加含 $\mathrm{IBCF}(44 \mu \mathrm{L}, 0.34$ $\mathrm{mmol}$ )的溶液 $1.5 \mathrm{~mL}$, 滴加完毕后继续摚拌反应 $8 \mathrm{~h}$. 加 少量水终止反应, 减压回收 $\mathrm{CH}_{2} \mathrm{Cl}_{2}$ 至干, 残留物用乙酸 乙酯 $(120 \mathrm{~mL})$ 和水 $(80 \mathrm{~mL})$ 分散, 萃取, 所得有机层依次 以 $0.1 \mathrm{~mol} \cdot \mathrm{L}^{-1}$ 酸水 $(80 \mathrm{~mL})$ 、饱和碳酸氢钠 $(80 \mathrm{~mL} \times 2)$ 和饱和氯化钠 $(80 \mathrm{~mL} \times 2)$ 洗涤, 无水硫酸镁干燥, 减压 回收溶剂至干, 所得残留物经硅胶柱层析 $[V($ 氯仿 $): V$ (甲 醇 $)=70 ：$ ] 纯化得无色油状中间体 12a. 参照上述方法 制得中间体 12b 12e.

$N$-( $N$-苯甲酰基-1-苯丙氨酰基)- $O$-( $2,3,4,6$-四- $O$-乙酰 基- $\beta$ - $D$-吡喃半乳糖基)-1-苯丙氨醇(12a): 无色油状物, 收率 $86 \%$. ${ }^{1} \mathrm{H}$ NMR $\left(400 \mathrm{MHz}, \mathrm{CDCl}_{3}\right) \delta: 7.77 \sim 7.70(\mathrm{~m}$, $2 \mathrm{H}, \mathrm{H}-3 \mathrm{~b}, \mathrm{H}-7 \mathrm{~b}$ ), $7.55 \sim 7.48$ (m, 1H, H- $5 \mathrm{~b}$ ), $7.48 \sim 7.40$ (m, 2H, H-4b, H-6b), $7.37 \sim 7.27$ (m, 5H, H-arom.), 7.24 7.14 (m, 3H, H-arom.), 7.12 7.07 (m, 2H, H-arom.), 6.86 (d, $J=7.6 \mathrm{~Hz}, 1 \mathrm{H}, \mathrm{NHCO}), 6.20(\mathrm{~d}, J=8.5 \mathrm{~Hz}, 1 \mathrm{H}$, NHCO), 5.39 (dd, $J=3.4,0.9 \mathrm{~Hz}, 1 \mathrm{H}, \mathrm{H}-4 \mathrm{~d}$ ), 5.24 (dd, $J=$ $10.5,7.9 \mathrm{~Hz}, 1 \mathrm{H}, \mathrm{H}-2 \mathrm{~d}$ ), 5.04 (dd, $J=10.5,3.4 \mathrm{~Hz}, 1 \mathrm{H}$, H-3d), $4.82 \sim 4.76(\mathrm{~m}, 1 \mathrm{H}, \mathrm{H}-2 \mathrm{a}), 4.33(\mathrm{~d}, J=7.9 \mathrm{~Hz}, 1 \mathrm{H}$, H-1d), 4.26 4.09 (m, 3H, H-2c, H-6d), 3.86 3.79 (m, 1H, H-5d), 3.64 (dd, $J=10.1,4.0 \mathrm{~Hz}, 1 \mathrm{H}, \mathrm{H}-1 \mathrm{c}$ ), 3.43 (dd, $J=10.1,3.0 \mathrm{~Hz}, 1 \mathrm{H}, \mathrm{H}-1$ 'c), 3.22 (dd, $J=13.6,5.7 \mathrm{~Hz}, 1 \mathrm{H}$, H-3a), 3.12 (dd, $J=13.6,7.8 \mathrm{~Hz}, 1 \mathrm{H}, \mathrm{H}-3$ 'a), $2.82 \sim 2.69$ (m, $2 \mathrm{H}, \mathrm{H}-3 \mathrm{c}), 2.16$ (s, 3H, $\mathrm{CH}_{3} \mathrm{CO}$ ), 2.11 (s, 3H, $\mathrm{CH}_{3} \mathrm{CO}$ ), 2.02 (s, 3H, $\left.\mathrm{CH}_{3} \mathrm{CO}\right), 2.01$ (s, 3H, $\left.\mathrm{CH}_{3} \mathrm{CO}\right) ;{ }^{13} \mathrm{C}$ NMR (101 $\left.\mathrm{MHz}, \mathrm{CDCl}_{3}\right) \delta: 170.39,170.20,170.13,169.46$, (C-1a, $\left.\mathrm{CH}_{3} \mathrm{CO} \times 4\right), 166.87(\mathrm{C}-1 \mathrm{~b}), 137.22,136.57,133.73$, $\left(3 \mathrm{C}_{\text {arom.quat. }}\right), 131.76$ (C-5b), $129.43 \quad\left(2 \mathrm{C}_{\text {arom. }}\right), 129.14$

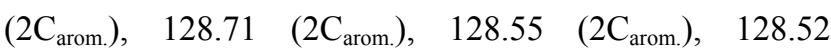
$\left(2 \mathrm{C}_{\text {arom. }}\right), 127.13$ ( $\left.\mathrm{C}_{\text {arom }}\right), 127.01$ (C-3b, C-7b), 126.60 (C-7c), 101.14 (C-1d), 70.62 (C-3d, C-5d), 69.03 (C-1c), 68.84 (C-2d), 66.94 (C-4d), 61.31 (C-6d), 54.79 (C-2a), $50.20(\mathrm{C}-2 \mathrm{c}), 38.64(\mathrm{C}-3 \mathrm{a}), 36.63(\mathrm{C}-3 \mathrm{c}), 20.86\left(\mathrm{CH}_{3} \mathrm{CO}\right)$, $20.66\left(\mathrm{CH}_{3} \mathrm{CO}\right), 20.59\left(\mathrm{CH}_{3} \mathrm{CO} \times 2\right)$.

$N$-( $N$-苯甲酰基-1-酪氨酰基)- $O$-(2,3,4,6-四- $O$-乙酰 基- $\beta$ - $D$ - 吡喃半乳糖基)-1-苯丙氨醇(12b): 无色油状物, 收率 91\%. ${ }^{1} \mathrm{H}$ NMR $\left(400 \mathrm{MHz}, \mathrm{CDCl}_{3}\right) \delta: 7.76(\mathrm{~d}, J=7.2$ Hz, 2H, H-3b, H-7b), 7.52 (t, $J=7.4$ Hz, 1H, H-5b), 7.44 (t, $J=7.5 \mathrm{~Hz}, 2 \mathrm{H}, \mathrm{H}-4 \mathrm{~b}, \mathrm{H}-6 \mathrm{~b}), 7.25 \sim 7.10$ (m, 7H, H-5a, H-9a, H-5c $\sim \mathrm{H}-9 \mathrm{c}$ ), 6.79 (d, $J=8.4 \mathrm{~Hz}, 2 \mathrm{H}, \mathrm{H}-6 \mathrm{a}, \mathrm{H}-8 \mathrm{a})$, $6.56(\mathrm{~d}, J=10.2 \mathrm{~Hz}, 1 \mathrm{H}, \mathrm{NHCO}), 6.22(\mathrm{~d}, J=8.6 \mathrm{~Hz}, 1 \mathrm{H}$, NHCO), 5.38 (dd, $J=3.4,0.9 \mathrm{~Hz}, 1 \mathrm{H}, \mathrm{H}-4 \mathrm{~d}$ ), 5.23 (dd, $J=$ $10.5,7.9 \mathrm{~Hz}, 1 \mathrm{H}, \mathrm{H}-2 \mathrm{~d}$ ), 5.03 (dd, $J=10.5,3.4 \mathrm{~Hz}, 1 \mathrm{H}$, $\mathrm{H}-3 \mathrm{~d}), 4.74 \sim 4.67(\mathrm{~m}, 1 \mathrm{H}, \mathrm{H}-2 \mathrm{a}), 4.30 \sim 4.21(\mathrm{~m}, 2 \mathrm{H}$, H-2c, H-6d), 4.19 (d, $J=7.9$ Hz, 1H, H-1d), 4.04 (dd, $J=$ $11.3,6.3 \mathrm{~Hz}, 1 \mathrm{H}, \mathrm{H}-6 \mathrm{~d}$ ), 3.75 (t, $J=6.6 \mathrm{~Hz}, 1 \mathrm{H}, \mathrm{H}-5 \mathrm{~d}$ ), 3.59 (dd, $J=10.3,3.4 \mathrm{~Hz}, 1 \mathrm{H}, \mathrm{H}-1 \mathrm{c}$ ), 3.42 (dd, $J=10.3$, $2.8 \mathrm{~Hz}, 1 \mathrm{H}, \mathrm{H}-1$ 'c), 3.13 (dd, $J=13.5,4.9 \mathrm{~Hz}, 1 \mathrm{H}, \mathrm{H}-3 \mathrm{a}$ ), 3.01 (dd, $J=13.5,8.8 \mathrm{~Hz}, 1 \mathrm{H}, \mathrm{H}-3 \mathrm{\prime}$ a), $2.82 \sim 2.70(\mathrm{~m}, 2 \mathrm{H}$, $\mathrm{H}-3 \mathrm{c}$ ), 2.18 (s, 3H, $\mathrm{CH}_{3} \mathrm{CO}$ ), 2.11 (s, 3H, $\mathrm{CH}_{3} \mathrm{CO}$ ), 2.02 (s, $3 \mathrm{H}, \mathrm{CH}_{3} \mathrm{CO}$ ), 1.98 (s, 3H, $\mathrm{CH}_{3} \mathrm{CO}$ ); ${ }^{13} \mathrm{C}$ NMR $(101 \mathrm{MHz}$, $\left.\mathrm{CDCl}_{3}\right) \delta: 170.89,170.44,170.29,170.25,169.58,(\mathrm{C}-1 \mathrm{a}$, $\left.\mathrm{CH}_{3} \mathrm{CO} \times 4\right), 166.82(\mathrm{C}-1 \mathrm{~b}), 155.30(\mathrm{C}-7 \mathrm{a}), 137.23(\mathrm{C}-4 \mathrm{c})$, 133.68 (C-2b), 131.81 (C-5b), 130.60 (2C $\left.\mathrm{C}_{\text {arom }}\right), 129.08$ $\left(2 \mathrm{C}_{\text {arom. }}\right), 128.57\left(2 \mathrm{C}_{\text {arom. }}\right), 128.52\left(2 \mathrm{C}_{\text {arom }}\right), 128.06$ (C-4a), 127.02 (C-3b，7b), 126.61 (C-7c), 115.82 (C-6a, 8a), 101.22 (C-1d), 70.67 (C-3d), 70.54 (C-5d), 69.58 (C-1c), 68.88 (C-2d), 66.98 (C-4d), 61.63 (C-6d), 55.43 (C-2a), 
50.21 (C-2c), 38.28 (C-3a), 36.49 (C-3c), 20.84, 20.66, $20.63,20.55,\left(\mathrm{CH}_{3} \mathrm{CO} \times 4\right)$.

$N$-( $N$ - 苯甲酰基- $O$-正已基-1-酪氨酰基)- $O$-(2,3,4,6四- $O$-乙酰基- $\beta$ - $D$-吡喃半乳糖基)-1-苯丙氨醇(12c): 无色 油状物, 收率 $80 \% .{ }^{1} \mathrm{H} \mathrm{NMR}\left(400 \mathrm{MHz}, \mathrm{CDCl}_{3}\right) \delta: 7.75 \sim$ 7.71 (m, 2H, H-3b, H-7b), 7.54 7.48 (m, 1H, H-5b), 7.43 (t, $J=7.5 \mathrm{~Hz}, 2 \mathrm{H}, \mathrm{H}-4 \mathrm{~b}, \mathrm{H}-6 \mathrm{~b}), 7.24 \sim 7.08$ (m, 7H, H-5a, H-9a, H-5c $\sim \mathrm{H}-9 \mathrm{c}$ ), 6.84 (d, $J=8.6 \mathrm{~Hz}, 2 \mathrm{H}, \mathrm{H}-6 \mathrm{a}, \mathrm{H}-8 \mathrm{a}$ ), $6.81(\mathrm{~d}, J=7.6 \mathrm{~Hz}, 1 \mathrm{H}, \mathrm{NHCO}), 6.23(\mathrm{~d}, J=8.5 \mathrm{~Hz}, 1 \mathrm{H}$, NHCO), 5.40 (dd, $J=3.4,0.8 \mathrm{~Hz}, 1 \mathrm{H}, \mathrm{H}-4 \mathrm{~d}$ ), 5.27 (dd, $J=$ $10.5,7.9 \mathrm{~Hz}, 1 \mathrm{H}, \mathrm{H}-2 \mathrm{~d}$ ), 5.03 (dd, $J=10.5,3.4 \mathrm{~Hz}, 1 \mathrm{H}$, H-3d), 4.76 (dd, $J=13.3,7.1 \mathrm{~Hz}, 1 \mathrm{H}, \mathrm{H}-2 \mathrm{a}), 4.40$ (d, $J=$ $7.9 \mathrm{~Hz}, 1 \mathrm{H}, \mathrm{H}-1 \mathrm{~d}), 4.26 \sim 4.12$ (m, 3H, H-2c, H-6d), $3.95 \sim 3.86$ (m, 3H, H-5d, OCH $\mathrm{CH}_{2} \mathrm{CH}_{2} \mathrm{CH}_{2} \mathrm{CH}_{2} \mathrm{CH}_{3}$ ), 3.71 (dd, $J=10.0,4.2 \mathrm{~Hz}, 1 \mathrm{H}, \mathrm{H}-1 \mathrm{c}$ ), 3.48 (dd, $J=10.0$, $3.1 \mathrm{~Hz}, 1 \mathrm{H}, \mathrm{H}-1$ 'c), $3.18 \sim 3.04$ (m, 2H, H-3a), $2.84 \sim 2.71$ (m, $2 \mathrm{H}, \mathrm{H}-3 \mathrm{c}), 2.15$ (s, 3H, $\left.\mathrm{CH}_{3} \mathrm{CO}\right), 2.11$ (s, $3 \mathrm{H}, \mathrm{CH}_{3} \mathrm{CO}$ ), $2.01\left(\mathrm{~s}, 6 \mathrm{H}, \mathrm{CH}_{3} \mathrm{CO} \times 2\right), 1.79 \sim 1.72\left(\mathrm{~m}, 2 \mathrm{H}, \mathrm{OCH}_{2} \mathrm{CH}_{2}-\right.$ $\left.\mathrm{CH}_{2} \mathrm{CH}_{2} \mathrm{CH}_{2} \mathrm{CH}_{3}\right), 1.48 \sim 1.40\left(\mathrm{~m}, 2 \mathrm{H}, \mathrm{OCH}_{2} \mathrm{CH}_{2} \mathrm{CH}_{2} \mathrm{CH}_{2}-\right.$ $\left.\mathrm{CH}_{2} \mathrm{CH}_{3}\right), 1.35 \sim 1.30\left(\mathrm{~m}, 4 \mathrm{H}, \mathrm{OCH}_{2} \mathrm{CH}_{2} \mathrm{CH}_{2} \mathrm{CH}_{2} \mathrm{CH}_{2}-\right.$ $\mathrm{CH}_{3}$ ), 0.90 ( $\mathrm{t}, J=7.0 \mathrm{~Hz}, 3 \mathrm{H}, \mathrm{OCH}_{2} \mathrm{CH}_{2} \mathrm{CH}_{2} \mathrm{CH}_{2} \mathrm{CH}_{2} \mathrm{CH}_{3}$ ); ${ }^{13} \mathrm{C}$ NMR $\left(101 \mathrm{MHz}, \mathrm{CDCl}_{3}\right) \delta: 170.36,170.29,170.25$, 170.11, 169.44, (C-1a, $\left.\mathrm{CH}_{3} \mathrm{CO} \times 4\right), 166.90(\mathrm{C}-1 \mathrm{~b}), 158.22$ (C-7a), 137.21 (C-4c), 133.79 (C-2b), 131.73 (C-5b), 130.41 (2C $\left.\mathrm{C}_{\text {arom }}\right), 129.17$ (2C $\left.\mathrm{C}_{\text {arom. }}\right), 128.54$ (C-4b, 6b), 128.51 ( $2 \mathrm{C}_{\text {arom. }}$ ), 128.11 (C-4a), 127.01 (C-3b, 7b), 126.60 (C-7c), 114.62 (C-6a, 8a), 101.14 (C-1d), 70.72 (C-3d), $70.70 \quad(\mathrm{C}-5 \mathrm{~d}), \quad 68.95 \quad(\mathrm{C}-1 \mathrm{c}), \quad 68.85 \quad(\mathrm{C}-2 \mathrm{~d}), \quad 67.92$ $\left(\mathrm{OCH}_{2} \mathrm{CH}_{2} \mathrm{CH}_{2} \mathrm{CH}_{2} \mathrm{CH}_{2} \mathrm{CH}_{3}\right), 66.92$ (C-4d), 61.24 (C-6d), 54.67 (C-2a), 50.21 (C-2c), 37.53 (C-3a), 36.65 (C-3c), $31.57\left(\mathrm{OCH}_{2} \mathrm{CH}_{2} \mathrm{CH}_{2} \mathrm{CH}_{2} \mathrm{CH}_{2} \mathrm{CH}_{3}\right), 29.21 \quad\left(\mathrm{OCH}_{2} \mathrm{CH}_{2}-\right.$ $\left.\mathrm{CH}_{2} \mathrm{CH}_{2} \mathrm{CH}_{2} \mathrm{CH}_{3}\right), \quad 25.69 \quad\left(\mathrm{OCH}_{2} \mathrm{CH}_{2} \mathrm{CH}_{2} \mathrm{CH}_{2} \mathrm{CH}_{2} \mathrm{CH}_{3}\right)$, $22.57\left(\mathrm{OCH}_{2} \mathrm{CH}_{2} \mathrm{CH}_{2} \mathrm{CH}_{2} \mathrm{CH}_{2} \mathrm{CH}_{3}\right), 20.86,20.66,20.61$, 20.59, $\left(\mathrm{CH}_{3} \mathrm{CO} \times 4\right), 14.02\left(\mathrm{OCH}_{2} \mathrm{CH}_{2} \mathrm{CH}_{2} \mathrm{CH}_{2} \mathrm{CH}_{2} \mathrm{CH}_{3}\right)$.

$N$-[ $N$-(4-氯苯甲酰基 ) $-O$ - 正丁基 -1- 酪氨酰 基]- $O$-(2,3,4,6-四- $O$-乙酰基- $\beta$ - $D$-吡喃半乳糖基)-1-苯丙 氨醇(12d): 白色粉末, 收率 76\%. m.p. 190 $192{ }^{\circ} \mathrm{C} ;{ }^{1} \mathrm{H}$ NMR (400 MHz, $\left.\mathrm{CDCl}_{3}\right) \delta: 7.68(\mathrm{~d}, J=8.5 \mathrm{~Hz}, 2 \mathrm{H}, \mathrm{H}-3 \mathrm{~b}$, H-7b), 7.40 (d, $J=8.5 \mathrm{~Hz}, 2 \mathrm{H}, \mathrm{H}-4 \mathrm{~b}, \mathrm{H}-6 \mathrm{~b}), 7.27 \sim 7.07$ (m, 7H, H-5a, H-9a, H-5c $\mathrm{H}-9 \mathrm{c}), 6.89 \sim 6.75(\mathrm{~m}, 3 \mathrm{H}$, H-6a, H-8a, NHCO), 6.14 (d, $J=8.4 \mathrm{~Hz}, 1 \mathrm{H}, \mathrm{NHCO}$ ), 5.40 (d, $J=3.0 \mathrm{~Hz}, 1 \mathrm{H}, \mathrm{H}-4 \mathrm{~d}), 5.27$ (dd, $J=10.5,7.9 \mathrm{~Hz}, 1 \mathrm{H}$, H-2d), 5.04 (dd, $J=10.5,3.4 \mathrm{~Hz}, 1 \mathrm{H}, \mathrm{H}-3 \mathrm{~d}$ ), 4.74 (dd, $J=$ 13.1, 7.1 Hz, 1H, H-2a), 4.39 (d, J=7.9 Hz, 1H, H-1d), $4.25 \sim 4.08(\mathrm{~m}, 3 \mathrm{H}, \mathrm{H}-2 \mathrm{c}, \mathrm{H}-6 \mathrm{~d}), 3.97 \sim 3.83(\mathrm{~m}, 3 \mathrm{H}$,
H-5d, $\mathrm{OCH}_{2} \mathrm{CH}_{2} \mathrm{CH}_{2} \mathrm{CH}_{3}$ ), 3.72 (dd, $J=9.9,4.0 \mathrm{~Hz}, 1 \mathrm{H}$, $\mathrm{H}-1 \mathrm{c}), 3.46$ (dd, $J=10.0,2.8 \mathrm{~Hz}, 1 \mathrm{H}, \mathrm{H}-1$ 'c), $3.17 \sim 3.02$ (m, 2H, H-3a), 2.84 2.68 (m, 2H, H-3c), 2.15 (s, 3H, $\mathrm{CH}_{3} \mathrm{CO}$ ), 2.11 (s, 3H, $\mathrm{CH}_{3} \mathrm{CO}$ ), 2.02 (s, $6 \mathrm{H}, \mathrm{CH}_{3} \mathrm{CO} \times 2$ ), $1.77 \sim 1.72\left(\mathrm{~m}, 2 \mathrm{H}, \mathrm{OCH}_{2} \mathrm{CH}_{2} \mathrm{CH}_{2} \mathrm{CH}_{3}\right), 1.54 \sim 1.40(\mathrm{~m}$, $2 \mathrm{H}, \mathrm{OCH}_{2} \mathrm{CH}_{2} \mathrm{CH}_{2} \mathrm{CH}_{3}$ ), 0.96 (t, $J=7.4 \mathrm{~Hz}, 3 \mathrm{H}, \mathrm{OCH}_{2}-$ $\mathrm{CH}_{2} \mathrm{CH}_{2} \mathrm{CH}_{3}$ ).

$N$-[N-(2-呋喃甲酰基)-1-酪氨酰基)]- $O$-(2,3,4,6-四- $O$ 乙酰基- $\beta$ - $D$-吡喃半乳糖基)-1-苯丙氨醇(12e): 无色油状 物, 收率 76\%. ${ }^{1} \mathrm{H} \mathrm{NMR}\left(400 \mathrm{MHz}, \mathrm{CDCl}_{3}\right) \delta: 7.46(\mathrm{~d}, J=$ $1.7 \mathrm{~Hz}, 1 \mathrm{H}, \mathrm{H}-5 \mathrm{~b}$ ), 7.24 7.09 (m, 8H, H-3b, H-5a, H-9a, H-5c $\sim \mathrm{H}-9 \mathrm{c}$ ), 6.78 (d, $J=8.4 \mathrm{~Hz}, 2 \mathrm{H}, \mathrm{H}-6 \mathrm{a}, \mathrm{H}-8 \mathrm{a}), 6.68 \sim$ 6.43 (m, 2H, H-4b, NHCO), 6.21 (d, $J=8.5 \mathrm{~Hz}, 1 \mathrm{H}$, NHCO), 5.38 (dd, $J=3.4,0.8 \mathrm{~Hz}, 1 \mathrm{H}, \mathrm{H}-4 \mathrm{~d}$ ), 5.22 (dd, $J=$ $10.5,7.9 \mathrm{~Hz}, 1 \mathrm{H}, \mathrm{H}-2 \mathrm{~d}$ ), 5.02 (dd, $J=10.5,3.4 \mathrm{~Hz}, 1 \mathrm{H}$, $\mathrm{H}-3 \mathrm{~d}), 4.69 \sim 4.61(\mathrm{~m}, 1 \mathrm{H}, \mathrm{H}-2 \mathrm{a}), 4.29 \sim 4.16(\mathrm{~m}, 3 \mathrm{H}$, H-1d, H-6d, H-2c), 4.04 (dd, J=11.3, 6.4 Hz, 1H, H-6'd), 3.75 (t, $J=6.5 \mathrm{~Hz}, 1 \mathrm{H}, \mathrm{H}-5 \mathrm{~d}$ ), 3.56 (dd, $J=10.3,3.5 \mathrm{~Hz}$, $1 \mathrm{H}, \mathrm{H}-1 \mathrm{c}$ ), 3.41 (dd, $J=10.3,2.9 \mathrm{~Hz}, 1 \mathrm{H}, \mathrm{H}-1$ 'c), 3.09 3.00 (m, 2H, H-3a), 2.80 2.72 (m, 2H, H-3c), 2.19 (s, 3H, $\mathrm{CH}_{3} \mathrm{CO}$ ), 2.10 (s, 3H, $\mathrm{CH}_{3} \mathrm{CO}$ ), 2.02 (s, 3H, $\mathrm{CH}_{3} \mathrm{CO}$ ), 2.00 (s, $\left.3 \mathrm{H}, \mathrm{CH}_{3} \mathrm{CO}\right) ;{ }^{13} \mathrm{C}$ NMR $\left(101 \mathrm{MHz}, \mathrm{CDCl}_{3}\right) \delta: 170.90$, $170.43,170.30,169.96,169.58,\left(\mathrm{C}-1 \mathrm{a}, \mathrm{CH}_{3} \mathrm{CO} \times 4\right)$, 157.80, 155.32, (C-1b, C-7a), 147.22 (C-2b), 144.34 (C-5b), 137.21 (C-4c), 130.55 (2C $\left.\mathrm{C}_{\text {arom. }}\right), 129.10$ (2C $\left.\mathrm{C}_{\text {arom. }}\right)$, $128.48\left(2 \mathrm{C}_{\text {arom. }}\right), 127.90(\mathrm{C}-4 \mathrm{a}), 126.56(\mathrm{C}-7 \mathrm{c}), 115.80$ (C-6a, 8a), 114.82 (C-3b), 112.16 (C-4b), 101.20 (C-1d), 70.69 (C-3d), 70.51 (C-5d), 69.54 (C-1c), 68.86 (C-2d), 66.96 (C-4d), 61.57 (C-6d), 54.70 (C-2a), 50.20 (C-2c), 38.28 (C-3a), 36.47 (C-3c), 20.83, 20.67, 20.63, 20.57, $\left(\mathrm{CH}_{3} \mathrm{CO} \times 4\right)$.

\subsection{7 目标化合物 $13 \mathrm{a} \sim 13 \mathrm{e}$ 的合成}

以目标化合物 13a 的合成为例. 取中间体 12a (100 $\mathrm{mg}, 0.14 \mathrm{mmol}$ )于反应瓶中, 加入 $3 \mathrm{~mL}$ 甲醇和 $0.5 \mathrm{~mL}$ 二 氯甲烷溶解, 缓慢加入甲醇钠 $\left(0.68 \mathrm{~mL}, 0.41 \mathrm{~mol} \cdot \mathrm{L}^{-1}\right.$, $0.28 \mathrm{mmol}$ ), 室温摚拌 $30 \mathrm{~min}$ 后, 搅拌下加入阳离子交 换树脂中和, 调节 $\mathrm{pH}$ 至 $5 \sim 6$, 过滤, 浓缩滤液至干, 所 得残留物经硅胶柱层析 $[V($ 氯仿 $): V$ (甲醇 $)=10: 1]$ 纯化 得目标化合物 13a. 参照上述方法制得目标化合物 $13 \mathrm{~b} \sim 13 \mathrm{e}$.

$N$-( $N$-苯甲酰基-1-苯丙氨酰基)- $O-(\beta-D$-吡喃半乳糖 基)-1-苯丙氨醇(13a): 白色粉末, 收率 91\%. m.p. 229 $231{ }^{\circ} \mathrm{C} ;{ }^{1} \mathrm{H}$ NMR $\left(400 \mathrm{MHz}, \mathrm{CD}_{3} \mathrm{OD}\right) \delta: 7.71 \sim 7.67(\mathrm{~m}$, 2H, H-3b, H-7b), 7.54 7.48 (m, 1H, H-5b), 7.43 (t, $J=$ $7.6 \mathrm{~Hz}, 2 \mathrm{H}, \mathrm{H}-4 \mathrm{~b}, \mathrm{H}-6 \mathrm{~b}$ ), $7.30 \sim 7.13$ (m, 9H, H-arom.), 
$7.11 \sim 7.05$ (m, 1H, H-arom.), 4.82 (dd, $J=8.9,6.2 \mathrm{~Hz}$, $1 \mathrm{H}, \mathrm{H}-2 \mathrm{a}), 4.25 \sim 4.17$ (m, 1H, H-2c), 4.08 (d, $J=7.7 \mathrm{~Hz}$, 1H, H-1d), $3.81 \sim 3.74$ (m, 2H, H-4d, H-6d), 3.72 3.66 (m, 2H, H-6'd, H-1c), 3.63 3.52 (m, 2H, H-2d, H-1'c), 3.42 (dd, $J=9.7,3.4 \mathrm{~Hz}, 1 \mathrm{H}, \mathrm{H}-3 \mathrm{~d}), 3.39 \sim 3.34$ (m, $1 \mathrm{H}$, H-5d), 3.14 (dd, $J=13.7,6.2 \mathrm{~Hz}, 1 \mathrm{H}, \mathrm{H}-3 \mathrm{a}$ ), $3.01 \sim 2.93$ (m, 2H, H-3'a, H-3c), 2.81 (dd, $J=13.6,7.8 \mathrm{~Hz}, 1 \mathrm{H}$, $\mathrm{H}-3 \mathrm{c}) ;{ }^{13} \mathrm{C}$ NMR (101 MHz, CD $\left.{ }_{3} \mathrm{OD}\right) \delta: 173.27$ (C-1a), 169.92 (C-1b), 139.65, 138.65, 135.30, (3C arom.quat. $\left._{\text {. }}\right), 132.85$ (C-5b), 130.55 ( $\left.2 \mathrm{C}_{\text {arom. }}\right), 130.44$ ( $\left.2 \mathrm{C}_{\text {arom. }}\right), 129.53$ ( $\left.2 \mathrm{C}_{\text {arom. }}\right)$, $129.49\left(2 \mathrm{C}_{\text {arom. }}\right), 129.30\left(2 \mathrm{C}_{\text {arom. }}\right), 128.47$ (C-3b, 7b), 127.80, 127.26, (2 $\left.\mathrm{C}_{\text {arom. }}\right), 105.46$ (C-1d), 76.55 (C-5d), 74.83 (C-3d), 72.54 (C-2d), 71.88 (C-1c), 70.22 (C-4d), 62.62 (C-6d), 56.70 (C-2a), 52.64 (C-2c), 38.98 (C-3a), 37.96 (C-3c); ESI-MS $m / z: 587.2[\mathrm{M}+\mathrm{Na}]^{+}$. ESI-HRMS calcd for $\mathrm{C}_{31} \mathrm{H}_{36} \mathrm{~N}_{2} \mathrm{O}_{8} \mathrm{Na}[\mathrm{M}+\mathrm{Na}]^{+}$587.2369, found 587.2371 .

$N$-( $N$ - 苯甲酰基-1-酪氨酰基)- $O$-( $\beta$ - $D$ - 吡喃半乳糖 基)-1-苯丙氨醇(13b): 白色粉末, 收率 76\%. m.p. 227 $229{ }^{\circ} \mathrm{C} ;{ }^{1} \mathrm{H}$ NMR (400 MHz, DMSO- $\left.d_{6}\right) \delta: 9.11(\mathrm{~s}, 1 \mathrm{H}$, $\mathrm{OH}), 8.40$ (d, $J=8.5 \mathrm{~Hz}, 1 \mathrm{H}, \mathrm{NHCO}), 7.89$ (d, $J=8.3 \mathrm{~Hz}$, $1 \mathrm{H}, \mathrm{NHCO}$ ), $7.80 \sim 7.75$ (m, 2H, H-3b, H-7b), $7.55 \sim 7.47$ (m, 1H, H-5b), 7.47 7.39 (m, 2H, H-4b, H-6b), 7.26 7.10 (m, 5H, H-5c $\sim \mathrm{H}-9 \mathrm{c}$ ), 7.07 (d, $J=8.5 \mathrm{~Hz}, 2 \mathrm{H}, \mathrm{H}-5 \mathrm{a}$, H-9a), 6.60 (d, $J=8.5 \mathrm{~Hz}, 2 \mathrm{H}, \mathrm{H}-6 \mathrm{a}, \mathrm{H}-8 \mathrm{a}$ ), 4.85 (d, $J=$ $4.6 \mathrm{~Hz}, 1 \mathrm{H}, \mathrm{OH}), 4.72(\mathrm{~d}, J=5.5 \mathrm{~Hz}, 1 \mathrm{H}, \mathrm{OH}), 4.63(\mathrm{t}, J=$ $5.5 \mathrm{~Hz}, 1 \mathrm{H}, \mathrm{OH}), 4.59 \sim 4.52(\mathrm{~m}, 1 \mathrm{H}, \mathrm{H}-2 \mathrm{a}), 4.36(\mathrm{~d}, J=$ $4.5 \mathrm{~Hz}, 1 \mathrm{H}, \mathrm{OH}), 4.10 \sim 4.01$ (m, $2 \mathrm{H}, \mathrm{H}-1 \mathrm{~d}, \mathrm{H}-2 \mathrm{c}), 3.63 \sim$ 3.39 (m, 5H, H-4d, H-6d, H-1c), 3.37 3.24 (m, 3H, H-2d, H-3d, H-5d), 2.95 (dd, $J=13.7,5.3 \mathrm{~Hz}, 1 \mathrm{H}, \mathrm{H}-3 \mathrm{a}$ ), $2.91 \sim$ 2.77 (m, 2H, H-3'a, H-3c), 2.69 (dd, $J=13.5,8.2 \mathrm{~Hz}, 1 \mathrm{H}$, $\left.\mathrm{H}-3{ }^{\prime} \mathrm{c}\right) ;{ }^{13} \mathrm{C}$ NMR (101 MHz, DMSO- $\left.d_{6}\right) \delta: 171.16$ (C-1a), 166.12 (C-1b), 155.63 (C-7a), 138.73 (C-4c), 134.13 (C-2b), 131.25 (C-5b), 130.10 (C-5a, 9a), 129.31 (2C arom.), 128.41 (C-4a), 128.17 ( $\left.2 \mathrm{C}_{\text {arom. }}\right), 128.03$ (2C $\left.\mathrm{C}_{\text {arom. }}\right), 127.41$ (C-3b, 7b), 125.93 (C-7c), 114.81 (C-6a, 8a), 103.74 (C-1d), 75.18 (C-5d), 73.36 (C-3d), 70.63 (C-2d), 69.63 (C-1c), 68.11 (C-4d), 60.45 (C-6d), 55.19 (C-2a), 50.26 (C-2c), 36.42 (C-3a), 36.34 (C-3c); ESI-MS m/z: 603.2 $[\mathrm{M}+\mathrm{Na}]^{+}$. ESI-HRMS calcd for $\mathrm{C}_{31} \mathrm{H}_{36} \mathrm{~N}_{2} \mathrm{O}_{9} \mathrm{Na}[\mathrm{M}+$ $\mathrm{Na}]^{+}$603.2319, found 603.2325.

$N$-( $N$-苯甲酰基- $O$-正己基-1-酪氨酰基)- $O$-( $\beta$ - $D$-吡喃 半乳糖基)-1-苯丙氨醇(13c): 白色粉末, 收率 $85 \%$. m.p. $242 \sim 244{ }^{\circ} \mathrm{C} ;{ }^{1} \mathrm{H}$ NMR (400 MHz, DMSO- $\left.d_{6}\right) \delta: 8.38$ (d, $J=8.4 \mathrm{~Hz}, 1 \mathrm{H}, \mathrm{NHCO}), 7.97(\mathrm{~d}, J=8.3 \mathrm{~Hz}, 1 \mathrm{H}, \mathrm{NHCO})$, $7.71(\mathrm{~d}, J=7.2 \mathrm{~Hz}, 2 \mathrm{H}, \mathrm{H}-3 \mathrm{~b}, \mathrm{H}-7 \mathrm{~b}), 7.50$ (t, $J=7.3 \mathrm{~Hz}$, 1H, H-5b), 7.42 (t, $J=7.4 \mathrm{~Hz}, 2 \mathrm{H}, \mathrm{H}-4 \mathrm{~b}, \mathrm{H}-6 \mathrm{~b}), 7.23 \sim$ 7.06 (m, 7H, H-5a, H-9a, H-5c $\sim \mathrm{H}-9 \mathrm{c}$ ), 6.74 (d, $J=8.6$ Hz, 2H, H-6a, H-8a), 4.60 4.51 (m, 1H, H-2a), 4.14 3.20 (m, $12 \mathrm{H}, \mathrm{H}-1 \mathrm{c}, \mathrm{H}-2 \mathrm{c}, \mathrm{H}-1 \mathrm{~d} \sim \mathrm{H}-6 \mathrm{~d}, \mathrm{OCH}_{2} \mathrm{CH}_{2} \mathrm{CH}_{2}-$ $\mathrm{CH}_{2} \mathrm{CH}_{2} \mathrm{CH}_{3}$ ), 2.95 2.76 (m, 3H, H-3a, H-3c), 2.66 (dd, $\left.J=13.6,8.2 \mathrm{~Hz}, 1 \mathrm{H}, \mathrm{H}-3^{\prime} \mathrm{c}\right), 1.65 \sim 1.55\left(\mathrm{~m}, 2 \mathrm{H}, \mathrm{OCH}_{2-}\right.$ $\mathrm{CH}_{2} \mathrm{CH}_{2} \mathrm{CH}_{2} \mathrm{CH}_{2} \mathrm{CH}$ ), $1.38 \sim 1.17$ (m, $6 \mathrm{H}, \mathrm{OCH}_{2} \mathrm{CH}_{2} \mathrm{CH}_{2}-$ $\left.\mathrm{CH}_{2} \mathrm{CH}_{2} \mathrm{CH}_{3}\right), 0.81$ (t, $J=6.8 \mathrm{~Hz}, 3 \mathrm{H}, \mathrm{OCH}_{2} \mathrm{CH}_{2} \mathrm{CH}_{2}-$ $\left.\mathrm{CH}_{2} \mathrm{CH}_{2} \mathrm{CH}_{3}\right) ;{ }^{13} \mathrm{C}$ NMR (101 MHz, DMSO- $\left.d_{6}\right) \delta: 171.74$ (C-1a), 166.99 (C-1b), 157.63 (C-7a), 139.01 (C-4c), 134.31 (C-2b), 131.98 (C-5b), 130.70 (2C arom), 130.25 $\left(2 \mathrm{C}_{\text {arom }}\right), 129.77$ (2C arom. $), 128.80$ (C-4b, 6b), 128.60 $\left(2 \mathrm{C}_{\text {arom }}\right), 127.80$ (C-3b, 7b), 126.54 (C-7c), 114.46 (C-6a, 8a), 104.13 (C-1d), 75.52 (C-5d), 73.70 (C-3d), 71.08 (C-2d), 70.27 (C-1c), 68.58 (C-4d), $67.75\left(\mathrm{OCH}_{2} \mathrm{CH}_{2} \mathrm{CH}_{2}-\right.$ $\mathrm{CH}_{2} \mathrm{CH}_{2} \mathrm{CH}_{3}$ ), 60.98 (C-6d), 55.63 (C-2a), 50.91 (C-2c), 36.83 (C-3a, C-3c), $31.44\left(\mathrm{OCH}_{2} \mathrm{CH}_{2} \mathrm{CH}_{2} \mathrm{CH}_{2} \mathrm{CH}_{2} \mathrm{CH}_{3}\right)$, $29.09\left(\mathrm{OCH}_{2} \mathrm{CH}_{2} \mathrm{CH}_{2} \mathrm{CH}_{2} \mathrm{CH}_{2} \mathrm{CH}_{3}\right), \quad 25.65\left(\mathrm{OCH}_{2} \mathrm{CH}_{2}-\right.$ $\left.\mathrm{CH}_{2} \mathrm{CH}_{2} \mathrm{CH}_{2} \mathrm{CH}_{3}\right), \quad 22.52 \quad\left(\mathrm{OCH}_{2} \mathrm{CH}_{2} \mathrm{CH}_{2} \mathrm{CH}_{2} \mathrm{CH}_{2} \mathrm{CH}_{3}\right)$, $14.36\left(\mathrm{OCH}_{2} \mathrm{CH}_{2} \mathrm{CH}_{2} \mathrm{CH}_{2} \mathrm{CH}_{2} \mathrm{CH}_{3}\right)$; ESI-MS $m / z: 687.2$ $[\mathrm{M}+\mathrm{Na}]^{+}$. ESI-HRMS calcd for $\mathrm{C}_{37} \mathrm{H}_{48} \mathrm{~N}_{2} \mathrm{O}_{9} \mathrm{Na}[\mathrm{M}+$ $\mathrm{Na}]^{+}$687.3258, found 687.3260 .

$N$-[ $N$-(4- 氯苯甲酰基 )- $O$ - 正 丁基 - 1 - 酪氨酰 基]- $O$-( $\beta$ - $D$-吡喃半乳糖基)-1-苯丙氨醇(13d): 白色粉末, 收率 85\%. m.p. 266 268 ${ }^{\circ} \mathrm{C} ;{ }^{1} \mathrm{H}$ NMR $(400 \mathrm{MHz}$, DMSO- $\left.d_{6}\right) \delta: 8.54(\mathrm{~d}, J=8.4 \mathrm{~Hz}, 1 \mathrm{H}, \mathrm{NHCO}), 7.96$ (d, $J=$ $8.3 \mathrm{~Hz}, 1 \mathrm{H}, \mathrm{NHCO}), 7.82 \sim 7.76(\mathrm{~m}, 2 \mathrm{H}, \mathrm{H}-3 \mathrm{~b}, \mathrm{H}-7 \mathrm{~b}$ ), $7.55 \sim 7.48(\mathrm{~m}, 2 \mathrm{H}, \mathrm{H}-4 \mathrm{~b}, \mathrm{H}-6 \mathrm{~b}), 7.26 \sim 7.08(\mathrm{~m}, 7 \mathrm{H}$, H-5a, H-9a, H-5c $\sim \mathrm{H}-9 \mathrm{c}), 6.76$ (d, $J=8.7 \mathrm{~Hz}, 2 \mathrm{H}, \mathrm{H}-6 \mathrm{a}$, H-8a), 4.88 (d, $J=4.4 \mathrm{~Hz}, 1 \mathrm{H}, \mathrm{OH}), 4.74$ (d, $J=5.0 \mathrm{~Hz}$, $1 \mathrm{H}, \mathrm{OH}), 4.66(\mathrm{t}, J=5.4 \mathrm{~Hz}, 1 \mathrm{H}, \mathrm{OH}), 4.62 \sim 4.53(\mathrm{~m}, 1 \mathrm{H}$, H-2a), 4.39 (d, $J=4.5 \mathrm{~Hz}, 1 \mathrm{H}, \mathrm{OH}), 4.11 \sim 3.98(\mathrm{~m}, 2 \mathrm{H}$, H-1d, H-2c), 3.86 (t, $J=6.5 \mathrm{~Hz}, 2 \mathrm{H}, \mathrm{OCH}_{2} \mathrm{CH}_{2} \mathrm{CH}_{2} \mathrm{CH}_{3}$ ), $3.67 \sim 3.24(\mathrm{~m}, 8 \mathrm{H}, \mathrm{H}-2 \mathrm{~d} \sim \mathrm{H}-6 \mathrm{~d}, \mathrm{H}-1 \mathrm{c}), 2.97 \sim 2.88(\mathrm{~m}$, 2H, H-3a), 2.85 (dd, $J=13.6,3.4 \mathrm{~Hz}, 1 \mathrm{H}, \mathrm{H}-3 \mathrm{c}$ ), 2.68 (dd, $\left.J=13.7,8.2 \mathrm{~Hz}, 1 \mathrm{H}, \mathrm{H}_{-3}{ }^{\prime} \mathrm{c}\right), 1.66 \sim 1.57(\mathrm{~m}, 2 \mathrm{H}$, $\left.\mathrm{OCH}_{2} \mathrm{CH}_{2} \mathrm{CH}_{2} \mathrm{CH}_{3}\right), \quad 1.43 \sim 1.32\left(\mathrm{~m}, \quad 2 \mathrm{H}, \quad \mathrm{OCH}_{2} \mathrm{CH}_{2}-\right.$ $\mathrm{CH}_{2} \mathrm{CH}_{3}$ ), 0.88 (t, $\left.J=7.4 \mathrm{~Hz}, 3 \mathrm{H}, \mathrm{OCH}_{2} \mathrm{CH}_{2} \mathrm{CH}_{2} \mathrm{CH}_{3}\right) ;{ }^{13} \mathrm{C}$ NMR (101 MHz, DMSO- $\left.d_{6}\right) \delta$ : 171.11 (C-1a), 165.24 (C-1b), $157.24 \quad$ (C-7a), 138.76, 136.20, 132.88,

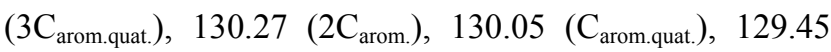
$\left(2 \mathrm{C}_{\text {arom }}\right), 129.40$ (2C $\left.\mathrm{C}_{\text {arom }}\right), 128.39$ (C-4b, 6b), 128.15 (2C $\left.\mathrm{C}_{\text {arom. }}\right), 126.07$ (C-7c), 114.05 (C-6a, 8a), 103.80 (C-1d), 75.29 (C-5d), 73.46 (C-3d), 70.72 (C-2d), 69.69 (C-1c), 
68.20 (C-4d), $67.04\left(\mathrm{OCH}_{2} \mathrm{CH}_{2} \mathrm{CH}_{2} \mathrm{CH}_{3}\right), 60.54$ (C-6d), 55.26 (C-2a), 50.42 (C-2c), 36.45 (C-3a, C-3c), 30.89 $\left(\mathrm{OCH}_{2} \mathrm{CH}_{2} \mathrm{CH}_{2} \mathrm{CH}_{3}\right), 18.84\left(\mathrm{OCH}_{2} \mathrm{CH}_{2}-\mathrm{CH}_{2} \mathrm{CH}_{3}\right), 13.81$ $\left(\mathrm{OCH}_{2} \mathrm{CH}_{2} \mathrm{CH}_{2} \mathrm{CH}_{3}\right)$; ESI-MS m/z: $693.2[\mathrm{M}+\mathrm{Na}]^{+}$. ESI-HRMS calcd for $\mathrm{C}_{35} \mathrm{H}_{43} \mathrm{ClN}_{2} \mathrm{O}_{9} \mathrm{Na}[\mathrm{M}+\mathrm{Na}]^{+}$ 693.2555, found 693.2549.

$N$-[ $N$-(2-呋喃甲酰基)-1-酪氨酰基]- $O-(\beta-D$-吡喃半乳 糖基)-1-苯丙氨醇(13e): 白色粉末, 收率 84\%. m.p. $190 \sim 192{ }^{\circ} \mathrm{C} ;{ }^{1} \mathrm{H}$ NMR $\left(400 \mathrm{MHz}, \mathrm{CD}_{3} \mathrm{OD}\right.$ ) $\delta$ : 7.65 (s, 1H, H-5b), $7.26 \sim 7.01$ (m, 8H, H-3b, H-5a, H-9a, H-5c H-9c), 6.67 (d, $J=8.4 \mathrm{~Hz}, 2 \mathrm{H}, \mathrm{H}-6 \mathrm{a}, \mathrm{H}-8 \mathrm{a}$ ), $6.58 \sim 6.55$ (m, 1H, H-4b), 4.70 (t, $J=7.3 \mathrm{~Hz}, 1 \mathrm{H}, \mathrm{H}-2 \mathrm{a}$ ), $4.21 \sim 4.14$ (m, 1H, H-2c), 4.09 (d, J=7.6 Hz, 1H, H-1d), 3.85 3.75 (m, 2H, H-6d, H-4d), 3.75 3.64 (m, 2H, H-6'd, H-1c), $3.59 \sim 3.51(\mathrm{~m}, 2 \mathrm{H}, \mathrm{H}-2 \mathrm{~d}, \mathrm{H}-1 \mathrm{c}), 3.48 \sim 3.38(\mathrm{~m}, 2 \mathrm{H}$, H-3d, H-5d), 2.98 (td, $J=13.8,6.7 \mathrm{~Hz}, 2 \mathrm{H}, \mathrm{H}-3 \mathrm{a}$ ), 2.86 (dd, $J=13.8,8.0 \mathrm{~Hz}, 1 \mathrm{H}, \mathrm{H}-3 \mathrm{c}$ ), 2.77 (dd, $J=13.5,7.8 \mathrm{~Hz}$, $\left.1 \mathrm{H}, \mathrm{H}-3{ }^{\prime} \mathrm{c}\right) ;{ }^{13} \mathrm{C}$ NMR (101 MHz, CD $\left.\mathrm{OD}\right) \delta: 173.02$ (C-1a), 160.08 (C-1b), 157.25 (C-7a), 148.50 (C-2b), 146.49 (C-5b), 139.62 (C-4c), 131.46 (2C arom.), 130.54 $\left(2 \mathrm{C}_{\text {arom. }}\right), 129.25$ (2C $\left.\mathrm{C}_{\text {arom }}\right), 128.96$ (C-4a), $127.22(\mathrm{C}-7 \mathrm{c})$, 116.27 (C-6a, 8a), 115.79 (C-3b), 113.07 (C-4b), 105.43 (C-1d), 76.58 (C-5d), 74.84 (C-3d), 72.56 (C-2d), 71.73 (C-1c), 70.26 (C-4d), 62.57 (C-6d), 56.12 (C-2a), 52.64 (C-2c), 38.36 (C-3a), 37.94 (C-3c); ESI-MS m/z: 593.2 [M $+\mathrm{Na}]^{+}$. ESI-HRMS calcd for $\mathrm{C}_{29} \mathrm{H}_{34} \mathrm{~N}_{2} \mathrm{O}_{10} \mathrm{Na}[\mathrm{M}+\mathrm{Na}]^{+}$ 593.2111, found 593.2115.

\section{3 药物对 HBV DNA 抑制试验}

取对数生长期的 2.2 .15 细胞, 用 $0.02 \%$ EDTA 清洗 两遍, 再用 $0.25 \%$ 胰蛋白酶消化后吹打均匀, 计数到 $2.5 \times 10^{5}$ 个细胞 $/ \mathrm{mL}$, 接种到 24 孔板中, 每孔 $0.5 \mathrm{~mL}$, 待细胞贴壁后开始给药. 样品用含 DMSO 的培养液配 制成 $12.5,25,50 \mu \mathrm{g} \cdot \mathrm{mL}^{-1}$ 这 3 个浓度, 加入 24 孔培养板 中, 每孔 $0.6 \mathrm{~mL}$, 每浓度 2 孔, 以加等量 DMSO 的培养 液代替药液的细胞为对照组. 给药第 $3 \mathrm{~d}$ 换同浓度药液, 给药第 $6 \mathrm{~d}$ 收集细胞. 用磷酸盐缓冲液( $\mathrm{PBS}$ )洗涤 2 次后, 用提取病毒核心颗粒试剂进行抽提. 采用 Taqman 探针 做荧光定量 PCR 测定细胞内 HBV DNA 含量. 按公式 HBV DNA 抑制率 $(\%)=($ 对照组拷贝数一给药组拷贝 数)/对照组拷贝数 $\times 100 \%$, 计算样品对细胞中 $\mathrm{HBV}$ DNA 复制的抑制率.

\section{辅助材料(Supporting Information) 目标化合物 13a} 13e 的 ${ }^{1} \mathrm{H}$ NMR 和 ${ }^{13} \mathrm{C}$ NMR 图谱. 这些材料可以免费从 本刊网站(http://sioc-journal.cn/)上下载.

\section{References}

[1] Pierre, V. D.; Zanetti, A. R.; Shouval, D.; Herck, K. V. Adv. Exp. Med. Biol. 2010, 659, 175.

[2] Xu, B.-X.; Huang, Z.-M.; Liu, C.-X.; Cai, Z.-G.; Pan, W.-D.; Cao, P.-X.; Hao, X.-J.; Liang, G.-Y. Bioorg. Med. Chem. 2009, 17, 3118.

[3] Qiu, J.-Y.; Xu, B.-X.; Huang, Z.-M.; Pan W.-D.; Cao P.-X.; Liu C.-X.; HaO, X.-J.; Song, B.-A.; Liang, G.-Y. Bioorg. Med. Chem. 2011, 19, 5352.

[4] Qiu, J.-Y.; Huang, Z.-M.; Pan, W.-D.; Cao, P.-X.; Liang, G.-Y. J. Chin. Pharm. Univ. 2012, 43, 390 (in Chinese). (邱净英, 黄正明, 潘卫东, 曹佩雪, 梁光义, 中国药科大学学 报, 2012, 43, 390.)

[5] Liang, G.-P.; Cao, P.-X.; Yang, X.-X.; Huang, Z.-M.; Liu Q.-C.; Liang, G.-Y.; Xu, B.-X. Chin. J. Org. Chem. 2014, 34, 973 (in Chinese).

(梁光平, 曹佩雪, 杨秀虾, 黄正明, 刘青川, 梁光义, 徐必学, 有机化学, 2014, 34, 973.)

[6] Spiess, M. Biochemistry 1990, 29, 10009

[7] Zhu, J.-Q.; Chen, H.; Wang, S.-R.; Li, Y.; Fang, W.-S. Chem. J. Chin. Univ. 2013, 34, 1660 (in Chinese).

(朱建勤, 陈晖, 王少戎, 李燕, 方唯硕, 高等学校化学学报, 2013, 34, 1660.)

[8] Huang, Z.-J.; Zhang, Y.-H.; Zhao, L.; Jing, Y.-W.; Lai, Y.-S.; Zhang, L.-Y.; Guo, Q.-L.; Yuan, S.-T.; Zhang, J.-J.; Chen, L.; Peng, S.-X.; Tian, J.-D. Org. Biomol. Chem. 2010, 8, 632.

[9] Huang, Z.-J.; Fu, J.-J.; Liu, L.; Sun, Y.-J.; Lai Y.-S.; Ji, H.; Kanus, E. E.; Tian, J.-D.; Zhang, Y.-H. Org. Biomol. Chem. 2012, 10, 3882.

[10] Krikor, B. J.; Zhang, Z.-W.; Xu, B.; Su, J.; Chen, B.; Wan, S.-B.; Wu, J.-H.; Jiang, T.; Moulay A, A. J. Eur. J. Med. Chem. 2012, 48, 143.

[11] Tsukida, T.; Moriyama, H.; Kurokawa, K.; Achiha, T.; Inoue, Y.; Kondo, H. J. Med. Chem. 1998, 41, 4279.

[12] Jain, R. K.; Locke, R. D.; Matta, K. L. Carbohydr. Res. 1993, 241, 165.

[13] Felpin, F. X.; Boubekeur, K.; Lebreton, J. J. Org. Chem. 2004, 69, 1497.

[14] Chuang, H.-Y.; Ren, C.-T.; Chao, C.-A.; Wu, C.-Y.; Shivatare, S. S.; Cheng, T. J.; Wu, C.-Y.; Wong, C. H. J. Am. Chem. Soc. 2013, 135, 11140.

[15] Nicolaou, K. C.; Seitz, S. P.; Papahatjis, D. P. J. Am. Chem. Soc. 1983, 105, 2430.

[16] Yao, N.-H.; He, W.-Y.; Lam, K. S.; Liu, G. J. Comb. Chem. 2004, 6, 214.

[17] Ishida, H.; Ando, H.; Ito, H.; Kiso, M.; Hasegawa, A. J. Carbohydr. Chem. 1997, 16, 413.

[18] Greene, T. W.; Wuts, P. G. M. In Protective Groups in Organic Synthesis, John Wiley \& Sons, Inc, New York, 1999, p. 564.

[19] Carocci, A.; Catalano, A.; Corbo, F.; Duranti, A.; Amoroso, R.; Franchini, C.; Lentini, G.; Tortorella, V. Tetrahedron: Asymmetry 2000, $11,3619$.

[20] Chen, N.; Xie, J. J. Org. Chem. 2014, 79, 10716.

[21] Cai, M.-S.; Li, Z.-J. In Carbohydrate Chemistry: Fundamentals, Reactions, Synthesis, Isolation and Structure., Chemical Industry Press, Beijing, 2006, p. 370 (in Chinese).

(蔡孟深, 李中军, 糖化学一一基础、反应、合成、分离及结构, 化学工业出版社, 北京, 2006, p. 370.)

[22] Pathigoolla, A.; Sureshan, K. M. Chem. Commun. 2014, 50, 317.

[23] Nasopolou, M.; Georgiadis, D.; Matziari, M.; Dive, V.; Yiotakis, A. J. Org. Chem. 2007, 72, 7222. 